\title{
The Role of Cytokinin During Infection of Arabidopsis thaliana by the Cyst Nematode Heterodera schachtii
}

\author{
Carly M. Shanks, ${ }^{1}$ J. Hollis Rice, ${ }^{2}$ Yan Zubo, ${ }^{3}$ G. Eric Schaller, ${ }^{3}$ Tarek Hewezi, ${ }^{2}$ and Joseph J. Kieber ${ }^{1}$ \\ ${ }^{1}$ Department of Biology, University of North Carolina, Chapel Hill, NC 27599, U.S.A.; ${ }^{2}$ Department of Plant Sciences, University \\ of Tennessee, Knoxville, TN 37996, U.S.A.; ${ }^{3}$ Department of Biological Sciences, Dartmouth College, Hanover, NH 03755, U.S.A.
}

Submitted 13 July 2015. Accepted 13 October 2015.

\begin{abstract}
Plant-parasitic cyst nematodes induce the formation of hypermetabolic feeding sites, termed syncytia, as their sole source of nutrients. The formation of the syncytium is orchestrated by the nematode, in part, by modulation of phytohormone responses, including cytokinin. In response to infection by the nematode Heterodera schachtii, cytokinin signaling is transiently induced at the site of infection and in the developing syncytium. Arabidopsis lines with reduced cytokinin sensitivity show reduced susceptibility to nematode infection, indicating that cytokinin signaling is required for optimal nematode development. Furthermore, lines with increased cytokinin sensitivity also exhibit reduced nematode susceptibility. To ascertain why cytokinin hypersensitivity reduces nematode parasitism, we examined the transcriptomes in wild type and a cytokinin-hypersensitive typeA arr Arabidopsis mutant in response to $H$. schachtii infection. Genes involved in the response to biotic stress and defense response were elevated in the type-A arr mutant in the absence of nematodes and were hyperinduced following $\boldsymbol{H}$. schachtii infection, which suggests that the Arabidopsis type-A arr mutants impede nematode development because they are primed to respond to pathogen infection. These results suggest that cytokinin signaling is required for optimal $H$. schachtii parasitism of Arabidopsis but that elevated cytokinin signaling triggers a heightened immune response to nematode infection.
\end{abstract}

Plant-parasitic cyst nematodes, Heterodera spp., are sedentary endoparasites of plant roots in many economically important plant species in which they cause tremendous yield losses (Barker and Koenning 1998; Chitwood 2003). These obligate biotrophs establish an intimate association with their host plants to maintain their sedentary lifestyle. After hatching, the infective second-stage juvenile (J2) of cyst nematodes penetrates the plant root and migrates toward the vascular tissues, in which it selects a single cell as an initial feeding cell. Soon after this initial selection, hundreds of neighboring cells are fused with the initial feeding cell through cell-to-cell fusion, resulting in the formation

C. M. Shanks and J. H. Rice contributed equally to this manuscript.

Corresponding authors: J. J. Kieber; Telephone: +1.919.962.4455; E-mail: jkieber@unc.edu; and T. Hewezi; Telephone: +1.865.974.7559; E-mail: thewezi@utk.edu

*The $\boldsymbol{e}$-Xtra logo stands for "electronic extra" and indicates that three supplementary figures and five supplementary table are published online.

(c) 2016 The American Phytopathological Society of a specialized multinucleated feeding site called a syncytium. The mechanisms through which cyst nematodes induce the redifferentiation of normal root cells into metabolically active syncytium cells are unclear but appear to involve proteinaceous stylet secretion of nematode effector proteins, which are considered the genetic determinants of nematode parasitism (Haegeman et al. 2012; Hewezi and Baum 2013). Genome-wide gene expression analysis of nematode-induced syncytia in Arabidopsis pointed to key roles of phytohormones and their downstream signaling pathways in the transition of infected root cells into metabolically active sinks (Szakasits et al. 2009). While molecular and genetic studies have supported a role of auxin and ethylene in the development of syncytia (Cabrera et al. 2015; Quentin et al. 2013), direct evidence supporting a functional role of cytokinins in syncytium formation and function is lacking.

Cytokinins are $N^{6}$-substituted adenine-derived plant hormones that regulate numerous plant growth and developmental processes, including shoot and root growth, stem-cell maintenance and differentiation, as well as the response to biotic and abiotic factors (Argueso et al. 2009; Kieber and Schaller 2014). The first committed step in cytokinin biosynthesis, catalyzed by isopentenyltransferases, is the formation of cytokinin ribotides/ribosides (Hirose et al. 2008), which are subsequently converted to the active, free base forms of cytokinins by the LONELY GUY (LOG) family of enzymes (Kuroha et al. 2009). Cytokinin signaling occurs via a multistep phosphorelay system that modulates gene transcription (Kieber and Schaller 2014) (Fig. 1A). Cytokinin binding to the Arabidopsis histidine kinase (AHK) receptors results in autophosphorylation of a conserved histidine residue (Inoue et al. 2001; Suzuki et al. 2001; Ueguchi et al. 2001; Yamada et al. 2001). This phosphate is subsequently transferred to a conserved aspartic acid residue within the AHK receiver domain and, then, to an Arabidopsis histidine-containing phosphotransfer protein (AHP) (Hutchison et al. 2006). The AHP finally transfer the phosphate to an aspartic acid residue within the receiver domain of the Arabidopsis response regulators (ARR). The ARR fall into two classes, the type-A ARR that are negative elements in cytokinin signaling (To et al. 2004) and the type-B ARR that are positive regulators of cytokinin signaling. Phosphorylation of the type-B ARR activates their DNA-binding domain and leads to transcription of cytokinin primary response genes, which include the type-A ARR (Argyros et al. 2008; Hwang and Sheen 2001).

Cytokinins have been implicated in multiple host-pathogen interactions and defense responses (Argueso et al. 2009; Choi et al. 2011; Naseem and Dandekar 2012; Robert-Seilaniantz et al. 2011). Some pathogens are capable of either synthesizing cytokinins, elevating endogenous cytokinin levels, or both, which is often linked to the success of the pathogen (Robert-Seilaniantz 
et al. 2007; Walters and McRoberts 2006). These include gallforming pathogenic bacteria such as agrobacterium (Claeys et al. 1978; Hwang et al. 2010), the biotrophic actinomycete Rhodococcus fascians (Pertry et al. 2009), and biotrophic fungal and bacterial pathogens that form green bionissia or green islands (López-Carbonell et al. 1998; Walters et al. 2008). In addition to altering plant development, pathogen-derived cytokinins may also act to either delay senescence, increase sink activity, or both. In some cases, increased cytokinin signaling is associated with increased pathogen success. For example, Rhodococcus fascians secretes a mix of cytokinins that cannot be degraded by the cytokinin oxidases, which are enzymes that degraded cytokinin, to induce the production of leafy galls (Depuydt et al. 2008; Pertry et al. 2009). Pretreatment of Arabidopsis with low levels of cytokinin enhances the number of pathogen spores produced by the oomycete Hyaloperonospora arabidopsis (Argueso et al. 2012). However, elevated cytokinins have also been linked to decreased pathogen success. For example, cytokinins promote resistance of Arabidopsis to Pseudomonas syringae, mediated in part via the direct interaction of the salicylic acid (SA) response factor TGA3 with ARR2, a type-B ARR (Choi et al. 2010). Further, mutants that are hypersensitive to cytokinin (e.g., type-A arr mutants) support reduced growth of Hyaloperonospora arabidopsis, likely a result of a heightened defense response (Argueso et al. 2012).

Cytokinins have been linked to the interaction of nematodes with plants. Both $H$. schachtii and Meloidogyne incognita (a root-knot nematode) produce cytokinins, predominantly benzyladenine and zeatin-type varieties (Bird and Loveys 1980; De Meutter et al. 2003; Dimalla and van Staden 1977). Infection of either Lotus japonicus or tomato with $M$. incognita induced expression of a cytokinin-responsive ARR5 reporter gene (Lohar et al. 2004). This induction was first observed when the $\mathrm{J} 2$ nematode reached the vascular bundles and persisted through the early development of the gall but, then, declined as the galls matured. Consistent with this, infection of rice with the root-knot nematode $M$. graminicola resulted in altered expression of many genes involved in cytokinin function (Kyndt et al. 2012). Overexpression of a cytokinin oxidase in transgenic hairy roots of $L$. japonicus resulted in a decrease in the number of galls produced by $M$. incognita (Lohar et al. 2004). Further, infection of Arabidopsis with $H$. schachtii resulted in the induction of the cytokinin-responsive $\mathrm{P}_{\mathrm{TCS}}$ :ER-GFP reporter 14 days after infection (Absmanner et al. 2013).
A

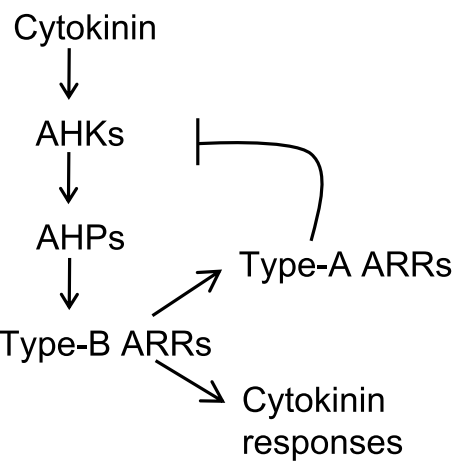

B
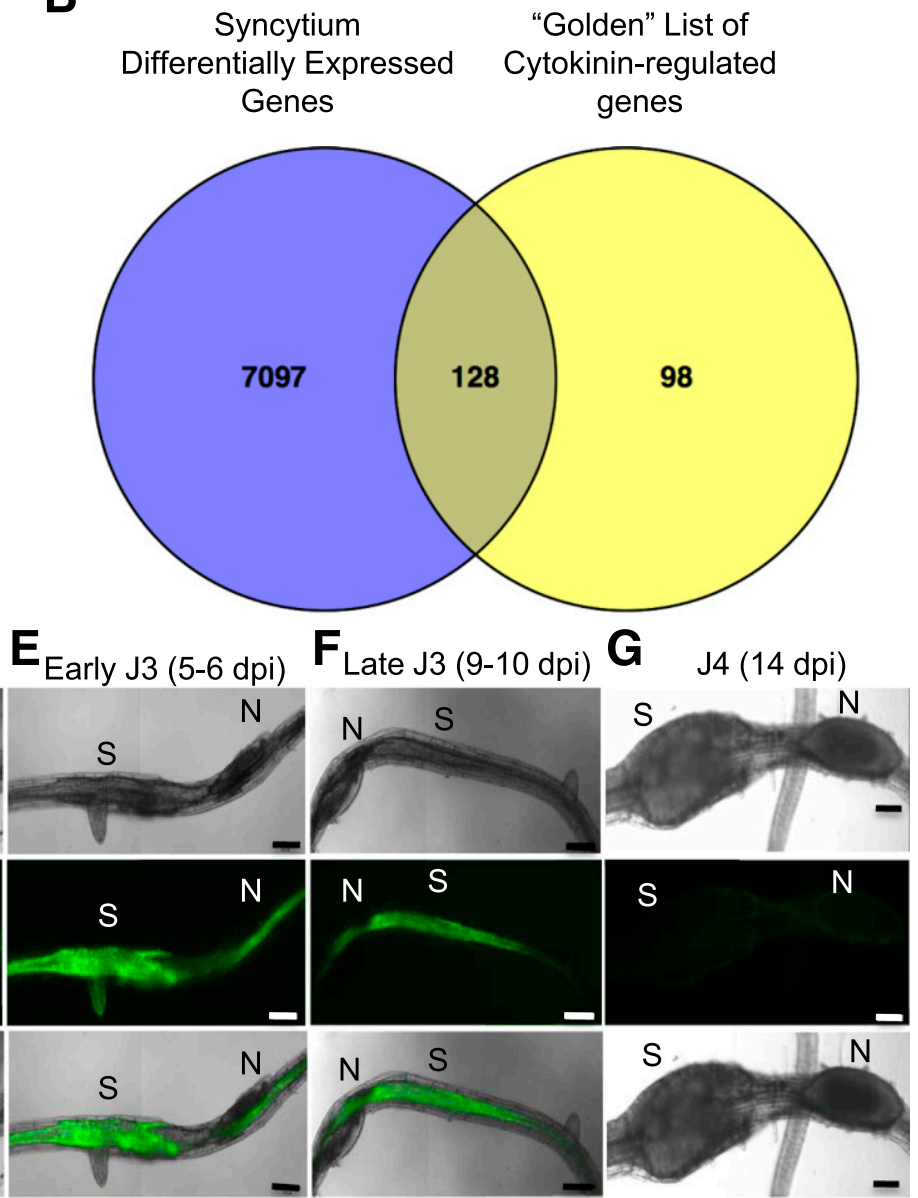

Fig. 1. Nematode infection elevates cytokinin signaling in the syncytium. A, Model of the cytokinin signaling pathway in Arabidopsis. Cytokinin binds to the Arabidopsis histidine kinase (AHKs) receptors and initiates a phosphorelay cascade, which phosphorylates the type-A and type-B Arabidopsis response regulators (ARR) via the histidine-containing phosphotransfer proteins (AHPs). The activated type-B ARR elevate transcription of cytokinin response genes, including the type-A ARR, which act as negative regulators of cytokinin signaling. B, Overlap between the 7,225 genes differentially expressed in Arabidopsis syncytia (Szakasits et al. 2009) and the 226 genes found in the 'golden' list, a set of robustly regulated cytokinin genes (Bhargava et al. 2013). Significant overlap between these two data sets was determined using the hypergeometric probability test $P(X \geq 128)=8.5 \mathrm{e}^{-26}$. C to $\mathbf{G}$, Visualization of TCSn::GFP reporter activity in the Heterodera schachtii-induced feeding sites compared with the noninfected plants. The top panels are differential interference contrast (DIC) images, the middle panels show the green fluorescent protein (GFP) signal, and the bottom panels the overlay. Noninfected roots (C), sedentary J2 at 2 to 3 days postinfection (dpi) (D), early $\mathrm{J} 3$ at 5 to $6 \mathrm{dpi}(\mathrm{E})$, late $\mathrm{J} 3$ at 9 to $10 \mathrm{dpi}(\mathrm{F})$, and $\mathrm{J} 4$ at $14 \mathrm{dpi}(\mathrm{G})$. $\mathrm{N}=$ nematode, $\mathrm{S}=$ syncytium, scale bars $=100(\mathrm{C}$ and $\mathrm{G})$ and $130 \mu \mathrm{m}(\mathrm{D}, \mathrm{E}$, and $\mathrm{F})$. 
Here, we examine the role of cytokinin signaling in the infection of Arabidopsis roots by the cyst nematode H. schachtii. Cytokinin signaling is up-regulated at the site of infection in response to $H$. schachtii. Several cytokinin-insensitive lines display reduced nematode susceptibility as measured by a reduced number of juvenile stage 4 (J4) females developing per root system. Interestingly, cytokinin-hypersensitive lines, such as the $\operatorname{arr} 3,4,5,6,7,8,9,15$ type-A ARR octuple mutant, are also less susceptible to nematode infection. These results demonstrate that precise modulation of cytokinin signaling is important for successful infection of Arabidopsis roots by H. schachtii.

\section{RESULTS}

\section{Cytokinin signaling is induced at the site of nematode infection.}

Syncytium formation is associated with extensive gene expression changes. Examination of 7,225 genes identified as differentially expressed in isolated syncytium cells induced by H. schachtii in Arabidopsis (Szakasits et al. 2009) revealed significant overlap (hypergeometric probability $P[\mathrm{X} \geq 128]=$ $8.5 \mathrm{e}^{-26}$ ) with a set of 226 robustly cytokinin-regulated genes, termed the 'golden' list (Bhargava et al. 2013) (Fig. 1B; Supplementary Table S1). A total of $64 \%$ of the 128 overlapping genes are regulated in the same manner, either up or down, in response to nematode infection and exogenous cytokinin, indicating that nematode infection likely increases cytokinin function in the host root. The similarly regulated genes include the cytokinin primary response gene $A R R 7$, which is a type-A ARR gene that is up-regulated by both cytokinin and nematode infection. The remaining $36 \%$ of the 128 overlapping genes that are regulated in opposite directions could reflect the fact that the syncytium data are pooled between 5 and 15 days postinfection (dpi) and there may be differing cytokinin-regulated responses in syncytium formation at these time-points. The significant overlap between genes robustly regulated by cytokinin and genes differentially expressed in response to nematode infection in the root suggest that nematodes alter cytokinin signaling as part of the infection process in Arabidopsis.

To explore the temporal and spatial changes in cytokinin signaling that take place in response to nematode infection, we inoculated 10-day-old seedlings of an Arabidopsis line that harbors the TCSn::GFP synthetic reporter, which reflects cytokinin-regulated type-B ARR activity (Zürcher et al. 2013), with $H$. schachtii J2 nematodes (Fig. 1C to G). A low level of fluorescence from green fluorescent protein (GFP) was observed in the vascular tissues of noninfected roots, while at 2 to 3 dpi by $H$. schachtii, during the parasitic J2 stage, a substantially elevated GFP fluorescence signal was observed both in the root tissues surrounding the nematode and at the site of the developing syncytium (Fig. 1D). The TCSn::GFP signal peaked in well-developed syncytia during the early $\mathrm{J} 3$ infective stage ( 5 to $6 \mathrm{dpi}$ ) and in the late J3 stage ( 9 to $10 \mathrm{dpi}$ ), and then, declined in the mature syncytium of J4 nematodes ( $14 \mathrm{dpi}$ ) to an intensity similar to the background levels observed in noninfected roots (Fig. 1E to G).

\section{Effects of cytokinin mutants on nematode infection.}

To further explore the role of cytokinin in plant susceptibility to $H$. schachtii infection, we examined mutants with altered cytokinin signaling. We first examined the effects of various cytokinin-insensitive mutants, including the cytokinin receptor mutants ahk4, ahk2,4, ahk2,3, and ahk3,4 (Cheng and Kieber 2013; Higuchi et al. 2004; Nishimura et al. 2004; Riefler et al. 2006), the ahpl,2,3 triple mutant (Hutchison et al. 2006), and the type-B ARR mutants arr 1-3,12-1, and arr1-3,10-2,12-1 (Mason et al. 2005). All of these cytokinin-insensitive lines exhibit reduced susceptibility to nematode infection compared with wild-type plants (Fig. 2). These results suggest that the canonical cytokinin signaling pathway is necessary for optimal nematode parasitism.

We next examined nematode susceptibility in lines disrupted for various type-A ARR genes, including the arr3,4,5,6, arr 3,4,5,6,7,8,9, and $\operatorname{arr} 3,4,5,6,7,8,9,15$ multiple mutants, which are hypersensitive cytokinin mutants (Fig. 3A). Previous studies have shown that the $\operatorname{arr} 3,4,5,6,7,8,9,15$ and $\operatorname{arr} 3,4,5,6,7,8,9$ lines are substantially more cytokinin hypersensitive as compared with the $\operatorname{arr} 3,4,5,6$ line (To et al. 2004; Zhang et al. 2011). These mutants have either no (arr3,4,5,6) or a modest effect on root growth and development in the absence of exogenous cytokinin (To et al. 2004; Zhang et al. 2011). We observed a significant nematode decrease in these lines that correlated to the level of cytokinin hypersensitivity (Fig. 3B to D). The arr3,4,5,6 mutant showed a $24 \%$ decrease in the number of $\mathrm{J} 4$ nematodes after 3 weeks of infection, the $\operatorname{arr} 3,4,5,6,7,8,9$ a $46 \%$ decrease, and the $\operatorname{arr} 3,4,5,6,7,8,9,15$ a $51 \%$ decrease.

To further test if cytokinin hypersensitivity affected nematode parasitism, we examined lines that exhibit hypersensitivity due to overexpression of $A R R 10$, a type-B ARR. Two independent transformants for $A R R 10$ overexpressed in a type-B arr1-3,10-5,12-1 mutant background were examined for cytokinin responsiveness and nematode susceptibility. Both lines (35S::ARR10\#A1 and 35S::ARR10\#A4) were hyper-responsive to exogenous cytokinin as determined by root-elongation assays (Fig. 3A). The parental arrl-3,10-5,12-1 line, which includes the more severe arr10-5 allele, has a greatly reduced root system as a result of strong cytokinin insensitivity (Hill et al. 2013), which precludes analysis of nematode infection for this line. Similar to the type-A ARR mutants, both of these cytokinin-hypersensitive lines displayed a significant decrease in nematode susceptibility relative to wild-type plants (Fig. 3E). Taken together, these results indicate that elevated cytokinin signaling is detrimental to nematode parasitism of Arabidopsis plants.

\section{RNA-Seq analysis of wild-type and $\operatorname{arr} 3,4,5,6,7,8,9,15$} mutant roots in response to nematode infection.

To address the mechanisms underlying the impaired nematode parasitism in the cytokinin hypersensitive mutants, we examined

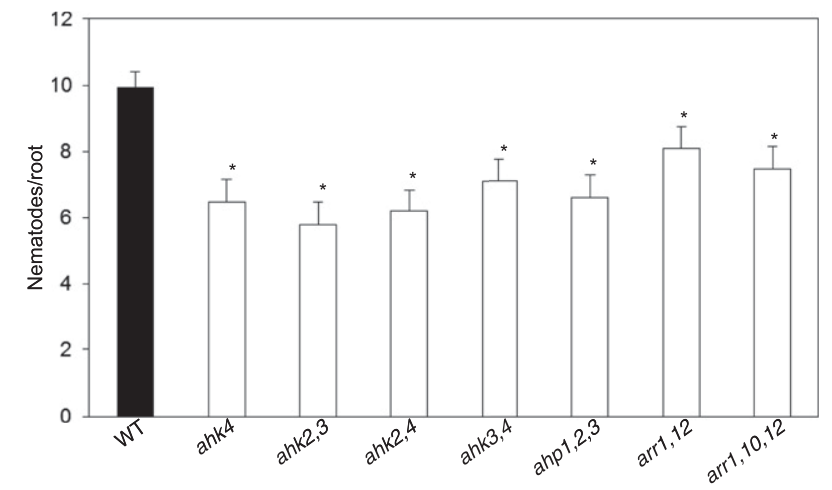

Fig. 2. Nematode susceptibility of cytokinin-insensitive mutants. Susceptibility assays of cytokinin insensitive mutant lines infected with Heterodera schachtii. The ahk4, ahk2,3, ahk3,4, ahk2,4, ahp1,2,3, arr1-3,12-1, and arr13,10-2,12-1 mutants were planted on modified Knop's medium and 10-dayold seedlings were inoculated with approximately 250 surface-sterilized J2 $H$. schachtii nematodes. The average number of $\mathrm{J} 4$ female nematodes per root system was determined 3 weeks postinoculation. Data are presented as mean number of J4 female nematodes per root system. Error bars represent standard error $(n=20)$. Mean values significantly different from the wild-type $(\mathrm{Col}-0)$ were determined using unadjusted paired $t$ tests $(P<0.05)$ and are indicated by asterisks. Similar results were obtained from at least two independent experiments. Data from one representative experiment are shown. 
the transcriptional profile of wild-type and arr3,4,5,6,7,8,9,15 octuple mutant roots in the absence and presence of nematodes, using RNA-sequencing during the syncytium formation and maintenance phases. Ten-day-old seedlings were infected with $\mathrm{J} 2 \mathrm{H}$. schachtii nematodes and three biological replicates of root tissue were collected at 4 (syncytium formation phase) and $10 \mathrm{dpi}$ (syncytium maintenance phase), along with the corresponding uninfected controls. There are 1,239 genes differentially regulated at 4 dpi in wild-type roots in response to infection, and 1,311 genes differentially regulated at $10 \mathrm{dpi}$ (false discovery rate $[\mathrm{FDR}]<0.05)$. ARR7 is up-regulated at 4 dpi in wild-type roots in response to nematode infection, which is consistent with the previous microarray study of nematodeinfected Arabidopsis roots (Supplementary Table S2) (Szakasits et al. 2009). Combining the two data sets yielded 2,067 genes differentially regulated in infected wild-type roots at 4 or

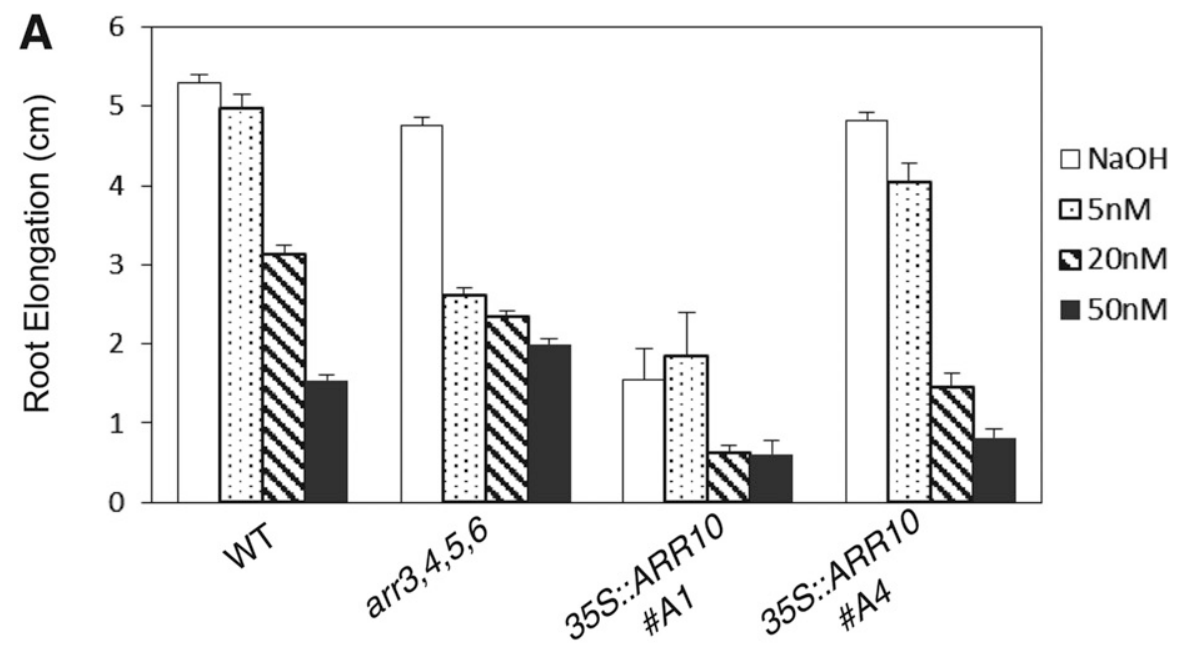

B

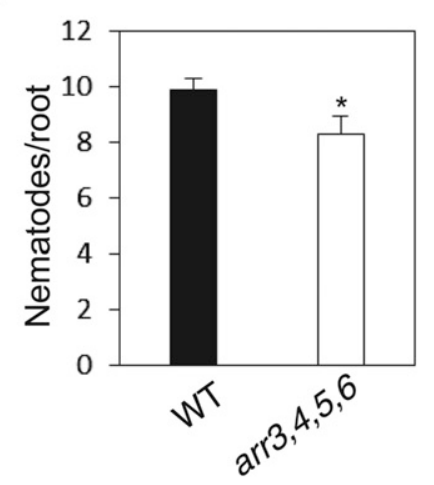

C
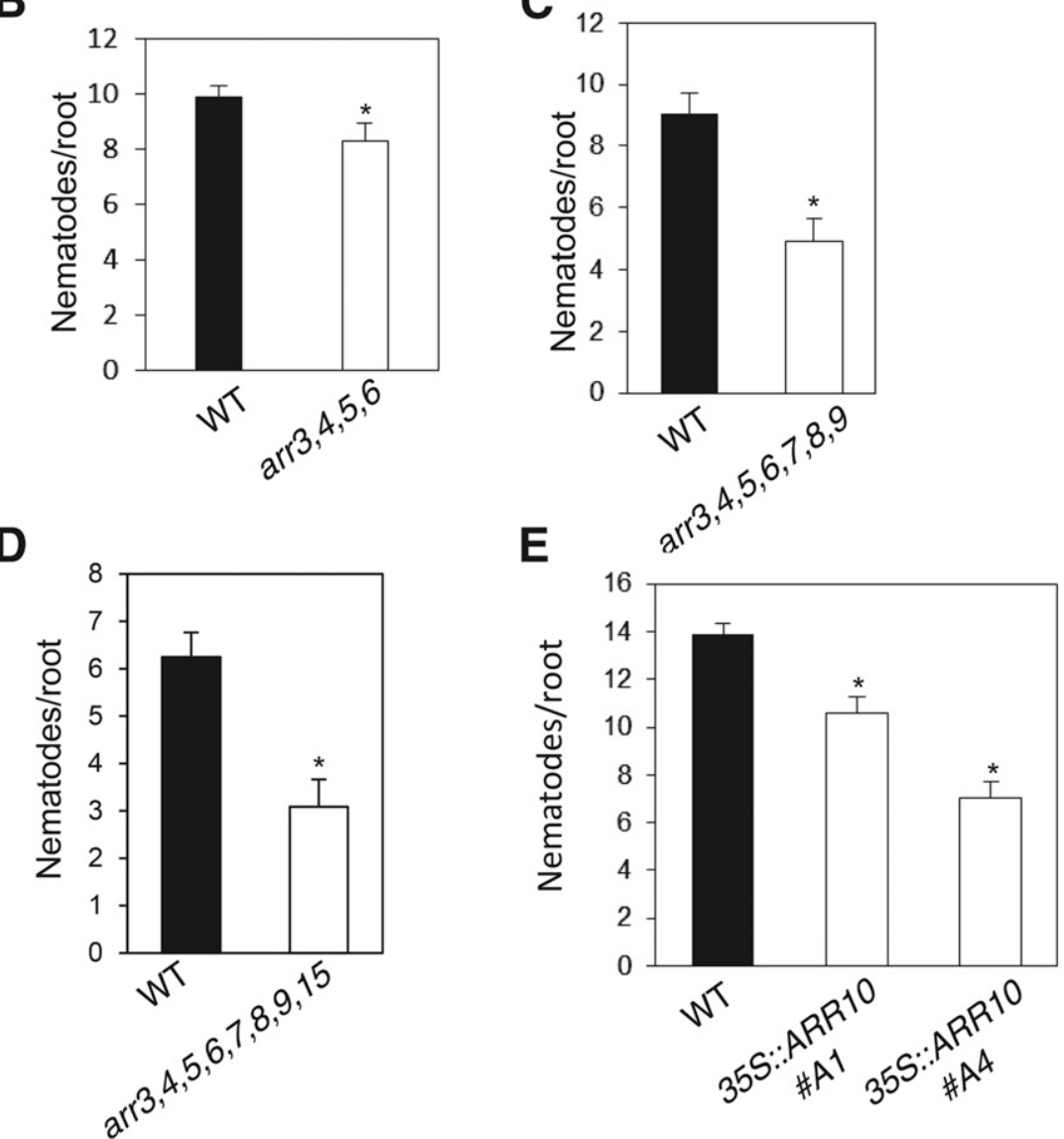

Fig. 3. Nematode susceptibility of cytokinin-hypersensitive mutants. A, Average root growth of wild type or the indicated mutants measured from days 4 to 9 . Seedlings grown on Murashige Skoog medium supplemented with the specified concentrations of benzyl adenine or $0.01 \% 5 \mathrm{~N} \mathrm{NaOH}$ vehicle control. Error bars represent standard error (SE) $(n>8)$. Similar results were obtained from at least two independent experiments. Data from one representative experiment are shown. B to E, Susceptibility assays of cytokinin mutant lines infected with Heterodera schachtii. Seeds of the arr3,4,5,6 mutants (B), arr3,4,5,6,7,8,9 mutants (C), arr3,4,5,6,7,8,9,15 mutants (D), and 35S::ARR10\#A1 and 35S::ARR10\#A4 (E) were planted on modified Knop's medium and were assayed for nematode susceptibility. Data are presented as mean \pm SE $(n=20)$. Significant differences from wild type (Col-0) were determined by unadjusted paired $t$ tests $(P<0.05)$ and are indicated by asterisks. Similar results were obtained from at least two independent experiments. 
$10 \mathrm{dpi}$, or both. These 2,067 genes were compared with those identified in a previous study of isolated syncytium cells induced by $H$. schachtii in Arabidopsis (Szakasits et al. 2009), which identified 7,225 genes differentially regulated in syncytia at one or both 5 or 15 dpi (Szakasits et al. 2009). There was significant overlap ( $43 \%$ of the genes identified as differentially expressed in response to infection in the current analysis were also identified in the prior study) between the two data sets (hypergeometric probability $P[X \geq 888] 1.29 \mathrm{e}^{-85}$ ) (Supplementary Fig. S1). However, the analysis here identified fewer differentially expressed genes, which likely reflects the use of entire roots rather than isolated syncytium tissue (Szakasits et al. 2009). A set of 1,179 genes were identified in the current study that were not identified in the isolated syncytium tissue, which could be due to identification of genes that were differentially regulated distal to the syncytium.

We next examined gene expression in the type-A arr3,4,5,6,7,8,9,15 mutant. In the absence of nematode infection, there were 4,822 genes differentially expressed in the 14-day-old (i.e., 4 days after mock inoculation) arr3,4,5,6,7,8,9,15 mutant roots compared with control wild-type roots $(2,224$ upregulated and 2,598 downregulated; FDR < 0.05). Similarly, 1,129 differentially expressed genes were identified in the 20-day-old (i.e., 10 days after mock inoculation) arr $3,4,5,6,7,8,9,15$ mutant roots compared with paired control wild-type roots (491 upregulated and 638 downregulated; FDR $<0.05)$. The substantial difference in the number of differentially expressed genes at these two time points suggests that type-A ARR may play a more substantial role early in root growth as compared with later developmental stages or may reflect compensatory changes in the arr $3,4,5,6,7,8,9,15$ mutant over developmental time.

Examination of these control gene sets revealed enrichment for genes involved in biotic stress (Fig. 4A and B). The MapMan analysis also points to an enrichment of genes involved in development following nematode infection, which may reflect
A

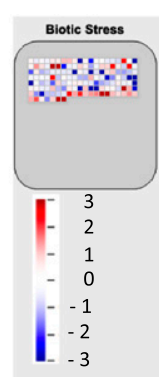

4 dpi control arr3,4,5,6,7,8,9,15 vs control WT
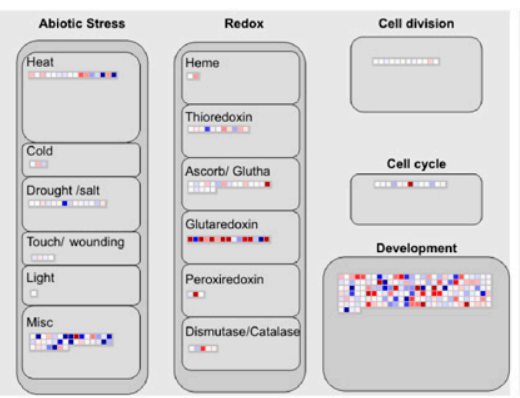

C

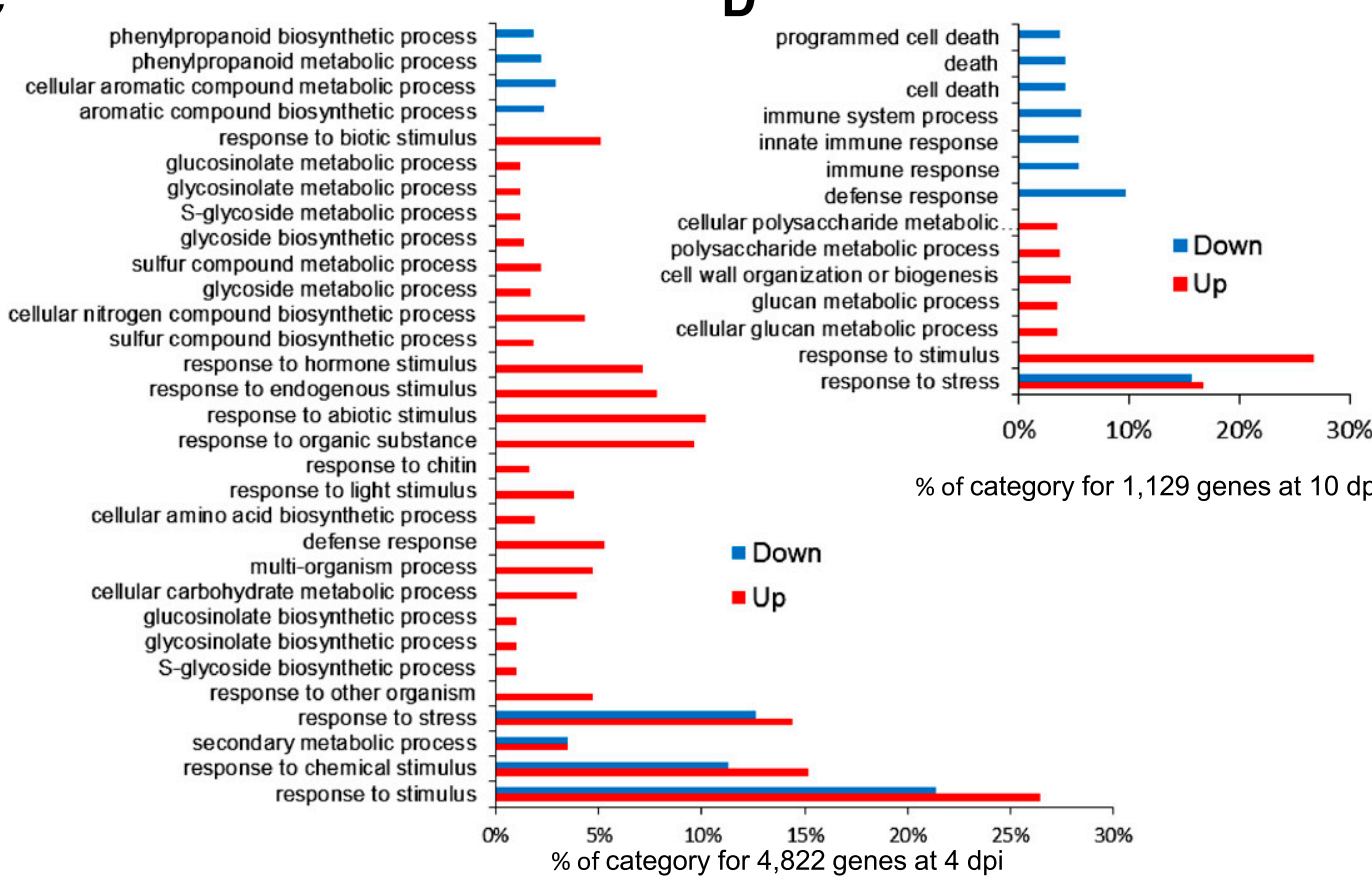

B 10 dpi control arr $3,4,5,6,7,8,9,15$ vs control WT

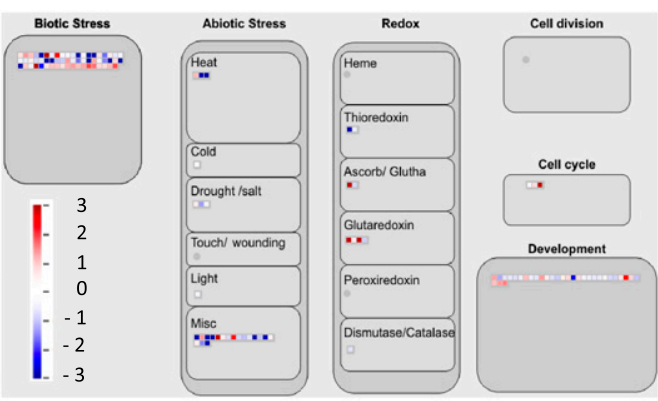

D

$\%$ of category for 1,129 genes at $10 \mathrm{dpi}$ 
the alteration of root development involved in the formation of syncytia. We separated the up- and downregulated genes for Gene Ontology (GO) analysis using the TAIR10 genome as a background population and GO biological process assignments by TAIR (The Arabidopsis Information Resource) and TIGR (The Institute for Genomic Research) annotation projects were used to explore potential processes affected in the arr $3,4,5,6,7,8,9,15$ mutant. In both the 14- and 20-day-old uninfected arr3,4,5,6,7,8,9,15 mutant samples, there is a significant enrichment $(P$ value $<$ 0.00001 ) for the GO terms 'response to stress' and 'defense response' in the differentially expressed gene sets (Fig. 4C and D). This suggests that defense genes are regulated in the arr $3,4,5,6,7,8,9,15$ mutant roots prior to infection by nematodes.

In the type-A arr3,4,5,6,7,8,9,15 mutant prior to infection, genes that are involved in SA defense signaling and cross-talk between jasmonic acid (JA) and ethylene (ET) plant defense responses were also identified (Table 1). For example, ENHANCED DISEASE SUSEPTIBILITY 1 (EDS1), which acts as a positive regulator of $\mathrm{SA}$ in defense signaling and a repressor of JA/ET signaling (Brodersen et al. 2006), is up-regulated in both uninfected arr3,4,5,6,7,8,9,15 samples. NON-RACE DISEASE RESISTANCE 1 (NDRl) is another positive regulator of SA in defense signaling (Shapiro and Zhang 2001), and this gene is up-regulated in type-A mutant roots. Free SA levels may be elevated in arr3,4,5,6,7,8,9,15 mutant roots, as the UDP-GLUCOSYLTRANSFERASE 74F2 (UGT74F2), which converts SA to the SA glucose ester (Dean and Delaney 2008), is down-regulated. Multiple WKRY transcription factors, which are regulated by SA signaling and which are involved in plant defense responses, were also regulated in the type-A arr3,4,5,6,7,8,9,15 mutant prior to infection. Among them, WRKY18 and WRKY40, which act downstream of EDS1 and SA as positive regulators of defense signaling (Schön et al. 2013), are both up-regulated in arr3,4,5,6,7,8,9,15 roots. Consistent with this, WRKY18 was previously found to be up-regulated in the type-A arr3,4,5,6,8,9 mutant (Argueso et al. 2012) WRKY62 and WKRY38 function additively as negative regulators of plant basal defense responses (Kim et al. 2008) and are down-regulated in the type-A arr3,4,5,6,7,8,9,15 mutant. This suggests that reduced expression of WRKY38 and WRKY62 may contribute to the enhanced resistance of the type-A arr mutants to infection. Overall, this data suggests that SA is positively regulated in the type-A arr $3,4,5,6,7,8,9,15$ mutant prior to infection, which is consistent with previous findings that type-A ARR negatively regulate the SA-induced defense response (Argueso et al. 2012).

While SA signaling responses are increased in the type-A arr3,4,5,6,7,8,9,15 mutant prior to infection, ET and JA signaling are decreased (Table 1). ACC SYNTHASE 11 (ACS11), which encodes a key enzyme in ethylene biosynthesis, is downregulated. There is also a decrease in expression of the JA biosynthesis enzyme ALLENE OXIDASE SYNTHASE (AOS) (Schaller 2001). We found that ETHYLENE RESPONSE FACTOR 1 (ERF1), which is activated by both JA and ET signaling and serves as a major link between the two pathways (Lorenzo et al. 2003), is down-regulated in the arr3,4,5,6,7,8,9,15 mutant. ET and JA signaling pathways positively regulate ERF2 expression (Lorenzo et al. 2003) and ERF2 is down-regulated in arr3,4,5,6,7,8,9,15. These results suggest that ET and JA signaling outputs are suppressed in the type-A arr3,4,5,6,7,8,9,15 mutant.

To confirm the upregulation of defense genes in the type-A arr $3,4,5,6,7,8,9,15$ mutant prior to infection, we used quantitative reverse transcription-polymerase chain reaction (qRT$\mathrm{PCR}$ ) to examine the expression of EDS1 in multiple type-A $\mathrm{arr}$ mutants (Supplementary Fig. S2). EDS1 expression is increased approximately twofold in both the arr3,4,5,6 and arr3,4,5,6,7,8,9,15 mutants as compared with the wild type, which is comparable to the differences found in the RNA-seq data. This confirms that EDS1 is up-regulated in lines disrupted for type-A ARR function.

Table 1. Biotic stress genes, salicylic acid, jasmonic acid, and ethylene signaling genes that were previously identified as key defense genes and are significantly differentially regulated in at least one treatment group ${ }^{\mathrm{a}}$

\begin{tabular}{|c|c|c|c|c|c|c|}
\hline & \multicolumn{2}{|c|}{ Control arr3,4,5,6,7,8,9,15 } & \multicolumn{2}{|c|}{ Infected wild type } & \multicolumn{2}{|c|}{ Infected arr $3,4,5,6,7,8,9,15$} \\
\hline & 4 dpi & 10 dpi & 4 dpi & 10 dpi & 4 dpi & 10 dpi \\
\hline \multicolumn{7}{|c|}{ Biotic stress genes } \\
\hline NDR1 & 0.66 & $\ldots$ & $\ldots$ & $\ldots$ & $\ldots$ & $\ldots$ \\
\hline PDF1.2 & $\ldots$ & $\ldots$ & $\ldots$ & $\ldots$ & 8.08 & $\ldots$ \\
\hline PDF1.2C & $\ldots$ & $\ldots$ & $\ldots$ & $\ldots$ & 6.04 & $\ldots$ \\
\hline EDS1 & 1.12 & 0.86 & $\ldots$ & $\ldots$ & $\ldots$ & $\ldots$ \\
\hline \multicolumn{7}{|c|}{ Salicylic acid genes } \\
\hline UGT74F2 & -1.04 & -0.85 & $\ldots$ & $\ldots$ & $\ldots$ & $\ldots$ \\
\hline \multicolumn{7}{|l|}{ Jasmonic acid } \\
\hline LOX3 & & & 2.36 & $\ldots$ & 1.76 & $\ldots$ \\
\hline AOS & -0.57 & -0.56 & 0.57 & $\ldots$ & $\ldots$ & $\ldots$ \\
\hline \multicolumn{7}{|l|}{ Ethylene } \\
\hline ERF1 & -1.16 & $\ldots$ & 0.90 & $\ldots$ & $\ldots$ & $\ldots$ \\
\hline ERF2 & -1.06 & -0.61 & 0.67 & $\ldots$ & $\ldots$ & $\ldots$ \\
\hline ERF104 & 0.91 & $\ldots$ & $\ldots$ & $\ldots$ & $\ldots$ & 0.75 \\
\hline ACS2 & $\ldots$ & $\ldots$ & 1.29 & $\ldots$ & 3.19 & 2.32 \\
\hline ACS6 & $\ldots$ & $\ldots$ & $\ldots$ & $\ldots$ & 1.03 & $\ldots$ \\
\hline ACS7 & $\ldots$ & $\ldots$ & 1.27 & $\ldots$ & 2.13 & \\
\hline ACS8 & $\ldots$ & $\ldots$ & $\ldots$ & $\ldots$ & 2.71 & 2.73 \\
\hline ACS11 & -0.93 & $\ldots$ & $\ldots$ & $\ldots$ & $\ldots$ & $\ldots$ \\
\hline \multicolumn{7}{|c|}{ WRKY transcription factors } \\
\hline WRKY18 & 1.08 & $\ldots$ & 1.00 & $\ldots$ & $\ldots$ & 0.93 \\
\hline WRKY23 & 1.18 & $\ldots$ & 0.72 & $\ldots$ & $\ldots$ & 0.89 \\
\hline WRKY38 & -1.79 & -0.99 & $\ldots$ & $\ldots$ & $\ldots$ & $\ldots$ \\
\hline WRKY40 & 1.33 & $\ldots$ & $\ldots$ & $\ldots$ & $\ldots$ & $\ldots$ \\
\hline WRKY46 & $\ldots$ & $\ldots$ & 1.50 & $\ldots$ & $\ldots$ & 1.45 \\
\hline WRKY62 & -2.20 & -2.17 & $\ldots$ & $\ldots$ & $\ldots$ & $\ldots$ \\
\hline
\end{tabular}


There are 1,831 genes differentially expressed between the infected $\operatorname{arr} 3,4,5,6,7,8,9,15$ mutant and infected wild-type roots at 4 dpi and 733 genes differentially expressed between the infected arr $3,4,5,6,7,8,9,15$ mutant and infected wild-type roots at 10 dpi by $H$. schachti (FDR < 0.05) (Fig. 5A and B). To identify genes that are specifically responsive to nematode infection, we focused on the genes that are found in the infected arr $3,4,5,6,7,8,9,15$ versus infected wild-type root gene set that do not overlap with the control arr $3,4,5,6,7,8,9,15$ versus control wild-type gene set. There are 668 such genes that are differentially regulated in the $\operatorname{arr} 3,4,5,6,7,8,9,15$ mutant at $4 \mathrm{dpi}$, but are not differentially regulated in uninfected control

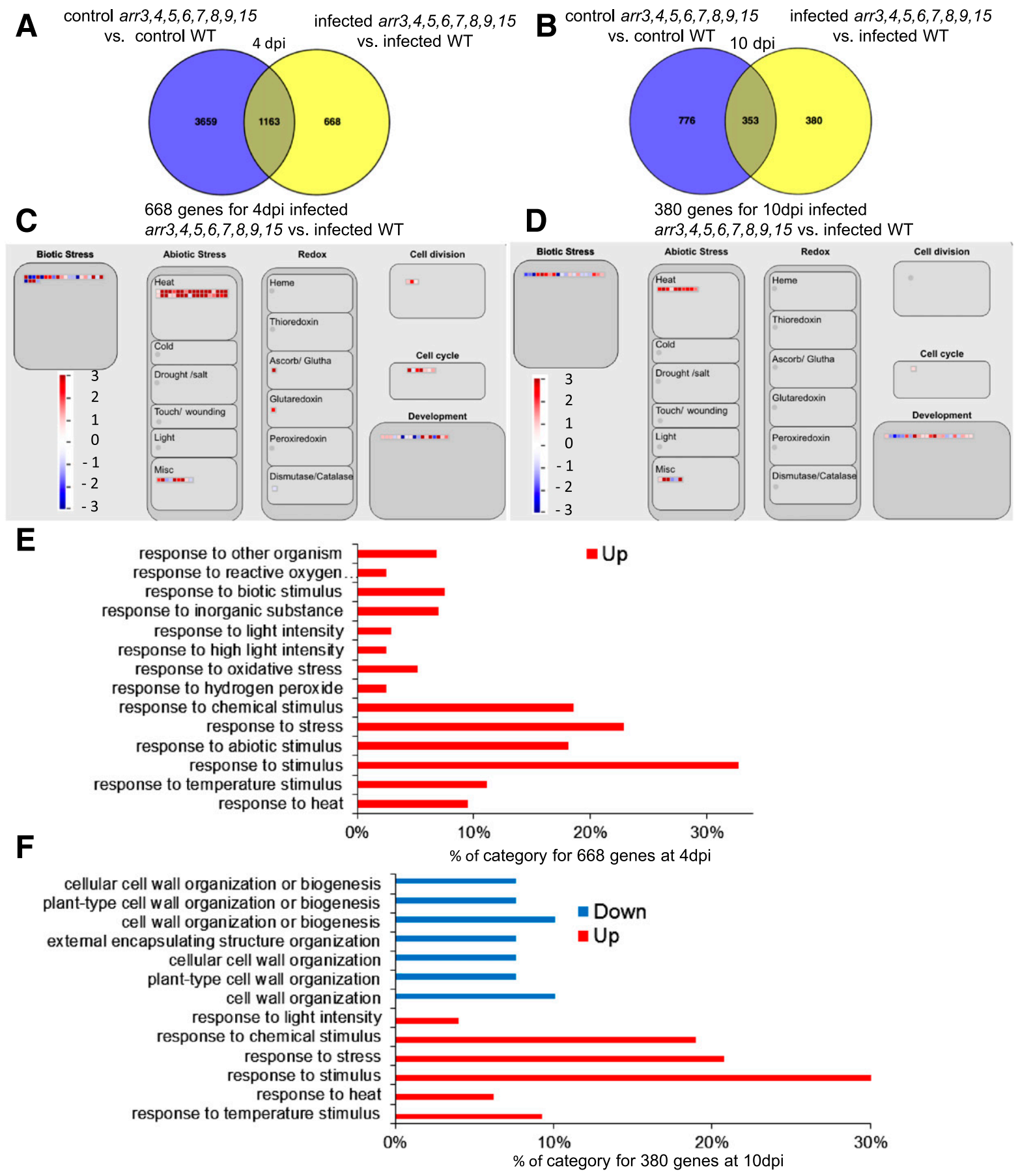

Fig. 5. The differentially expressed genes between the infected type-A arr3,4,5,6,7,8,9,15 mutant and infected wild type. A, Genes differentially expressed control type-A arr $3,4,5,6,7,8,9,15$ versus control wild type at 4 days (4,822 genes) or $\mathbf{B}, 10$ days $(1,129$ genes) after mock infection, compared with those differentially expressed between type-A arr3,4,5,6,7,8,9,15 and wild type 4 days after infection (dpi) (1,831 genes) or 10 dpi (733) with Heterodera schachtii. C, MapMan (Thimm et al. 2004) illustrations of the cellular response overview for the genes in A or B identified as differentially expressed and only found in the infected arr $3,4,5,6,7,8,9,15$ mutants at 4 dpi (668 genes) or $\mathbf{D}, 10$ dpi (380 genes). The red boxes $=$ upregulated genes and the blue boxes $=$ downregulated genes. Scale $=\log$ arithmic fold change from 3 to -3 . False discovery rate $<0.05$. E, Gene ontology (GO) analysis of the genes from A and B and used in the MapMan analysis at 4 dpi (668 genes) or F, 10 dpi (380 genes), made using the BioMaps tool on the VirtualPlant 1.3 software (Katari et al. 2010) for gene sets separated into upregulated and downregulated genes. Background population; TAIR10 genome, classification scheme: GO biological process assignments by TAIR/TIGR, Fisher exact test $(P<0.00001)$. The percentage of the observed frequency of genes found in each category is plotted on the $x$ axis. The blue bars $=$ enriched downregulated categories, the red bars = enriched upregulated categories. If there is no blue or red bar for a given category, it was not enriched at $P$ value $<0.00001$. 
arr3,4,5,6,7,8,9,15 versus control wild-type roots (500 upregulated, 168 downregulated) (Fig. 5A; Supplementary Table S3). A similar comparison at $10 \mathrm{dpi}$ identified 380 genes that are specifically differentially regulated in the infected arr3,4,5,6,7,8,9,15 mutant (245 upregulated and 135 downregulated) (Fig. 5B; Supplementary Table S4). These differentially expressed genes provide insight into molecular differences during the course of nematode infection in the mutant. Examination of these gene sets revealed enrichment for genes involved in biotic stress and the response to abiotic and heat stress (Fig. 5C and D). Similar to the analysis of uninfected gene sets, GO analysis indicates a significant enrichment for genes involved in the 'response to stress' at 4 and at $10 \mathrm{dpi}$ and 'response to biotic stimulus' at $4 \mathrm{dpi}(P$ values $<0.00001)$ (Fig. $5 \mathrm{E}$ and $\mathrm{F})$. This is consistent with an enhanced defense response in the arr3,4,5,6,7,8,9,15 mutant in response to nematode infection.

We identified genes that are involved in the JA and ET signaling defense pathways that are hyperinduced in infected type-A arr 3,4,5,6,7,8,9,15 mutants compared with infected wildtype roots, though these were generally distinct from those identified as altered in type-A arr3,4,5,6,7,8,9,15 noninfected roots (Table 1). At 4 and at $10 \mathrm{dpi}$, multiple $A C S$ genes are elevated, which suggests an increase in ethylene synthesis in response to infection. ETHEYLENE RESPONSE FACTOR 104 (ERF104), which is downstream of ET signaling, is upregulated in the infected data set at $10 \mathrm{dpi}$. LIPOGENASE 3 (LOX3), which is elevated in response to nematode parasitism and is necessary for JA synthesis, is also hyperinduced in infected arr3,4,5,6,7,8,9,15 roots, suggesting that JA signaling may be up-regulated (Ozalvo et al. 2014). A downstream target of both the ET and JA defense signaling pathways, PLANT DEFENSIN1.2 (PDF1.2) (Penninckx et al. 1998), is hyperinduced in infected $\operatorname{arr} 3,4,5,6,7,8,9,15$ roots. These results are somewhat distinct from what was found in the noninfected roots in which more SA signaling and defense response genes are up-regulated than ET and JA genes.

We also found enrichment for 'response to heat', which is a category not found in the analysis of the control wild-type versus arr3,4,5,6,7,8,9,15 mutant plants (Fig. 4). There are multiple heat shock proteins (HSP) that are hyperinduced in infected type-A arr3,4,5,6,7,8,9,15 roots (Supplementary Table S5). For example, HSP22, HSP17.4, and HSP18.2 are all upregulated at both 4 and 10 dpi in mutant versus the wild-type roots. We also find additional HSP up-regulated specifically at $4 \mathrm{dpi}$, including $H S P 70 b$ and $H S P 101$. There are also more cell wall-related categories that are down-regulated at $10 \mathrm{dpi}$, whereas there was one cell-wall category up-regulated ('cell wall organization and biogenesis') in the 10 dpi control wildtype versus arr $3,4,5,6,7,8,9,15$ mutant plants. This might reflect changes related to cell-wall remodeling during syncytium formation. There are only 48 genes that overlap between the genes differentially regulated at 4 and $10 \mathrm{dpi}$ in the arr3,4,5,6,7,8,9,15 mutant versus wild type (Supplementary Fig. S3). This low number of overlapping genes indicates that type-A ARR regulate distinct sets of genes during syncytium initiation and formation (4 dpi) and maintenance stages (10 dpi).

\section{DISCUSSION}

The infection of roots by cyst nematodes results in wholesale reprograming of the host transcriptome to modify the development and physiology to form a feeding site known as a syncytium. Phytohormones, which are involved in essentially all growth and developmental processes, play important roles in feeding site development (Cabrera et al. 2015; Quentin et al.
2013). Previous studies have examined changes in the response to the phytohormone cytokinin during syncytial development by examining the expression of a cytokinin-inducible ARR5 reporter (Lohar et al. 2004) or have noted enrichment of genes involved in cytokinin function among nematode-induced changes in the host transcriptome (Ithal et al. 2007; Kyndt et al. 2012). Further, nematodes have been shown to produce cytokinins (Bird and Loveys 1980; De Meutter et al. 2003; Dimalla and van Staden 1977). These studies, coupled with the role of cytokinin in promoting sink activity, suggested a role for cytokinins in nematode infection. Here, we demonstrate an enrichment of cytokinin-responsive genes in the set of genes differentially expressed in Arabidopsis roots in response to infection by the nematode $H$. schachtii. Consistent with this, the TCSn:GFP cytokinin response reporter indicates a transient rise in cytokinin signaling that correlates with the development of the syncytium, suggesting a role for cytokinin in this process. Absmanner et al. (2013) also noted an induction of a similar cytokinin-responsive $\mathrm{P}_{\mathrm{TCS}}$ :ER-GFP reporter following infection of Arabidopsis roots with $H$. schachtii and found that this $\mathrm{P}_{\mathrm{TCS}}$ :ER-GFP reporter was induced primarily in the phloem cells associated with the syncytia rather than throughout the developing syncytia, as we observe here (Absmanner et al. 2013). However, these authors only examined a single time point (14 days after infection), a point at which we observe little or no fluorescence from the TCSn:GFP reporter (Fig. 1). The differences in TCS expression could reflect our use of a newer version of the TCS reporter (Zürcher et al. 2013), differences in growth conditions, or both.

Cytokinin regulates a wide variety of biological processes (Argueso et al. 2009; Kieber and Schaller 2014; Mok and Mok 2001), many of which are relevant to the development and function of the syncytium. The pattern of expression of the TCSn:GFP reporter provides clues regarding potential roles of cytokinin in syncytial function. At early stages of infection (2 to $3 \mathrm{dpi}$ ), the TCSn:GFP signal was observed both in the young syncytium and in the surrounding cells. The elevation of cytokinin could play a role in promoting sink activity in these neighboring cells prior to their integration with the developing syncytium. However, at later stages of infection, the TCSn:GFP signal was reduced in the adjacent cells and became more localized to the fully developed syncytium. As cytokinin plays a critical role in the early stage of cambial cell differentiation that gives rise to xylem and phloem cells (Hejátko et al. 2009; Matsumoto-Kitano et al. 2008), the elevated cytokinin signaling in the neighboring cells could also be associated with the induction of sieve elements and companion cells around the syncytium to accelerate nutrient supply (Absmanner et al. 2013; Hoth et al. 2005). Consistent with this model, a recent study has demonstrated that sieve elements surrounding syncytium cells are formed de novo and are cytokinin-responsive as revealed by expression of the $\mathrm{P}_{\mathrm{TCS}}$ :ER-GFP reporter as noted above (Absmanner et al. 2013).

Cytokinin-insensitive lines exhibit compromised nematode susceptibility, which suggests that cytokinin signaling is necessary for optimal syncytium function. Mutants with increased sensitivity to cytokinin also show reduced nematode parasitism. The reduced nematode susceptibility does not simply reflect the shorter roots of some of these mutants, as previous studies have indicated that changes in nematode susceptibility levels are independent of root length or root mass over a wide range of phenotypes (Hewezi et al. 2008, 2012, 2015; Wubben et al. 2001). Rather, analysis of gene expression suggests that this is the result of a heightened defense response in the cytokininhypersensitive mutants.

Examination of the genes that are specifically regulated by $H$. schachtii in the type-A arr mutant provides clues as to how 
nematode parasitism is altered in this mutant. For example, we observed a significant enrichment of genes encoding HSP in the genes induced specifically in the arr $3,4,5,6,7,8,9,15$ mutant, including AtHsp90.1 and HSP90.2. HSP are highly conserved proteins and their expression is induced in response to a wide range of physiological and environmental stimuli (Ahuja et al. 2010). HSP play crucial roles as molecular chaperones by facilitating correct folding of stress-induced misfolded proteins (Wang et al. 2004). Several HSP were found to be upregulated during the resistant interaction of soybean with the soybean cyst nematode $H$. glycines (Kandoth et al. 2011). In addition, a number of studies have shown that HSP90 plays a key role in effector-triggered immunity in various pathosystems (Hubert et al. 2003; Takahashi et al. 2003; Thao et al. 2007; Shirasu 2009). Thus, the upregulation of HSP in the infection of the type-A ARR mutants may reflect an induction of defense responses in this mutant.

Another category enriched in genes regulated specifically in nematode-treated $\operatorname{arr} 3,4,5,6,7,8,9,15$, primarily at $10 \mathrm{dpi}$, are those encoding cell wall-modifying enzymes. The plant cell wall is a dynamic structure that undergoes significant remodeling during syncytium formation and development, and a large number of genes encoding cell wall-modifying enzymes are regulated in response to nematode infection in wild-type roots (Bohlmann and Sobczak 2014). In the arr3,4,5,6,7,8,9,15 mutant roots, a large number of such genes are expressed at a lower level as compared with nematode-infected wild-type roots at 10 dpi. This may reflect an altered ability of the nematodes to induce appropriate modifications of cell-wall architecture in the host prior to the cell fusions involved in the formation of the syncytium. There are also a number of genes encoding pectin methylesterase inhibitors altered in the $\operatorname{arr} 3,4,5,6,7,8,9,15$ mutant roots. Pectin methylesterases play a role in plant susceptibility to cyst nematodes, as an effector from $H$. schachtii has been shown to activate pectin methylesterase 3 in Arabidopsis to promote parasitism (Hewezi et al. 2008).

The type-A ARR and, by inference, cytokinin likely play an important role in the transcriptional reprogramming of the host plant in response to $H$. schachtii infection. This is reflected in the regulation of various transcription factors belonging to particular gene families in a stage-specific manner. While transcription factors of the MYB and BHLH families are the most abundant transcription factor families differentially expressed in the arr $3,4,5,6,7,8,9,15$ mutant in response to nematode infection at $4 \mathrm{dpi}, \mathrm{C} 2 \mathrm{H} 2$-type zinc finger and WRKY families are the most abundant at 10 dpi. Many of these transcription factors are involved in defense signaling pathways. For example, both MYB108 and MYB30, which are involved in wound-inducible cell death (Cui et al. 2013) and cell deathassociated responses (Canonne et al. 2011), respectively, are highly upregulated in the arr $3,4,5,6,7,8,9,15$ mutant in response to nematode infection at $4 \mathrm{dpi}$. Several WRKY transcription factors that are involved in the activation of SA biosynthesis genes (WRKY46) (van Verk et al. 2011), positive regulation of effector-triggered immunity (WRKY18) (Schön et al. 2013), and syncytium formation (WRKY23) (Grunewald et al. 2008) are upregulated in the $\operatorname{arr} 3,4,5,6,7,8,9,15$ mutant in response to nematode infection at $10 \mathrm{dpi}$. We concluded that cytokinin plays a role in the modulation of host genes in response to nematode infection, at least partly, through the regulation of transcription factors in a stage-specific manner.

The decreased nematode susceptibility of the type-A ARR mutants is similar to the interaction of Arabidopsis with the oomycete Hyaloperonospora arabidopsidis, in which type-A ARR mutants displayed slightly elevated expression of defense genes in the shoots prior to infection and a hyperinduction of these genes in response to infection with the pathogen (Argueso et al. 2012). Indeed, numerous genes encoding pathogenesisrelated proteins are hyperinduced in the arr3,4,5,6,7,8,9,15 mutant in response to nematode, including several plant defensins (PDF1.2A, PDF1.2C, PDF1.1, PDF1.4), PR-2, PR-6, and a thaumatin superfamily protein. Together, these data suggest that nematodes must walk a fine line between elevating cytokinin function sufficiently to promote optimal syncytial development but below levels that would trigger a strong defense response.

\section{MATERIALS AND METHODS}

\section{Plant materials and treatment conditions.}

All Arabidopsis lines used in this study are in the Colombia (Col-0) ecotype. The insertion alleles used for nematode susceptibility assays for the $a h k$ mutants are $a h k 2-7, a h k 3-3$, and cre1-12 (ahk4) (Higuchi et al. 2004), the ahpl,2,3 mutant (Hutchison et al. 2006), the arr1-3,12-1 and arrl-3,10-2,12-1 mutants (Mason et al. 2005), the arr3,4,5,6 mutant (To et al. 2004), and the $\operatorname{arr} 3,4,5,6,7,8,9$ and $\operatorname{arr} 3,4,5,6,7,8,9,15$ mutants (Zhang et al. 2011). To generate the Cauliflower mosaic virus 35S:ARR10-GFP construct, the ARR10 coding region was amplified from genomic DNA, using the primers $5^{\prime}$ TCCATAAATGAGTTAATTCGCCAGTCTTGAAG-3' and 5' -AGCTGACAAAGAAAAGGGAAAATGGAGTTTC-3', was cloned into the entry vector pCR8/ GW/TOPO/ (Invitrogen, Carlsbad, CA, U.S.A.), and then, was recombined into pEarleygate103 (Earley et al. 2006) using the Gateway system. For plant transformation, the construct was introduced into Agrobacterium tumefaciens GV3101 and was then transformed into the arr 1-3 arr10-5 arr12-1 mutant by the floral-dip method (Clough and Bent 1998).

\section{Root elongation assays.}

Seeds were surface-sterilized with chlorine gas, were plated on square vertical plates containing half Murashige and Skoog (MS) salts, $1 \%$ sucrose, and $0.6 \%$ phytagel (Sigma, St. Louis). Plates were cold-treated for 3 days in the dark at $4{ }^{\circ} \mathrm{C}$ and were then moved to $22^{\circ} \mathrm{C}$ at constant light for 4 days. On day 4,12 seedlings were transferred to half MS plates with $1 \%$ sucrose and $0.6 \%$ phytogel containing $5 \mathrm{nM}, 20 \mathrm{nM}$, or $50 \mathrm{nM}$ of benzyl adenine or $0.01 \% 5 \mathrm{~N} \mathrm{NaOH}$ as a vehicle control, and root length was marked. Plates were returned to $22^{\circ} \mathrm{C}$ and constant light for 5 days. On day 9 , plates were scanned and root growth between days 4 and 9 was measured, using ImageJ software (Abramoff et al. 2004). The average length of root growth was calculated for each genotype and treatment.

\section{Activity of TCSn::GFP reporter in response to $H$. schachtii infection.}

Transgenic Arabidopsis seeds expressing the TCSn::GFP reporter construct (Zürcher et al. 2013) were planted on 12-well tissue culture plates containing modified Knop's. Ten-day-old seedlings were inoculated with approximately 150 surfacesterilized $\mathrm{J} 2 \mathrm{H}$. schachtii nematodes per plant. The reporter activity was visualized by GFP fluorescence at different time points after $H$. schachtii infection. Bright field and fluorescent images of infected and noninfected control plants were observed and captured as previously described (Hewezi et al. 2014).

\section{Nematode susceptibility assays.}

Arabidopsis seeds were surface-sterilized with bleach and were planted in a random-block design on 12-well tissue culture plates (Corning Life Sciences, Tewksbury, MA, U.S.A) containing modified Knop's medium (Sijmons et al. 1991), solidified with $0.8 \%$ Daishin agar (Research Products International Corp., Mount Prospect, IL, U.S.A.). Plants were 
grown at $24^{\circ} \mathrm{C}$ under 16 -h-light and 8 -h-dark conditions. Tenday-old seedlings were inoculated with approximately 250 surface-sterilized $\mathrm{J} 2 \mathrm{H}$. schachtii nematodes per plant, as previously described (Baum et al. 2000). The inoculated plants were maintained under the same conditions described above. At 3 weeks postinoculation, the number of $\mathrm{J} 4$ female nematodes in each root system was counted to quantify plant susceptibility. Each line was replicated 20 times, and at least two independent experiments were carried out. Average numbers of J4 female nematodes per root system were calculated, and values significantly different from the wild type were determined in a modified $t$ test, using the statistical software package SAS $(P<0.05)$.

\section{RNA-Seq analysis.}

Wild-type Arabidopsis (Col-0) and the arr3,4,5,6,7,8,9,15 mutants were planted in culture dishes on modified Knop's medium, using a randomized complete-block design with three independent replications. Ten days after planting, the seedlings were inoculated with approximately 100 surface-sterilized J2 $H$. schachtii nematodes per plant. Then, root tissues were collected from both infected and noninfected plants at 4 and $10 \mathrm{dpi}$ with $H$. schachtii for RNA isolation and library preparation. Total RNA was extracted from three biological replicates for each of the control wild-type roots, infected wild-type roots, control type-A arr octuple mutant roots, and infected type-A arr octuple mutant roots (24 samples total), using the RNeasy Plus kit as described by the manufacturer (Qiagen, Hilden, Germany). RNA was DNAse treated with the TURBO DNAfree kit according to the manufacturer's instructions (Life Technologies, Carlsbad, CA, U.S.A.), and RNA was cleaned with RNeasy Plus kit, as described by the manufacturer (Qiagen). Sample concentrations were determined using the NanoDrop and were sent to the High-Throughput Sequencing Center at the University of North Carolina, Chapel Hill. The cDNA libraries were prepared using the TruSeq Stranded mRNA preparation kit according to manufacturer's instructions (Illumina, San Diego, CA, U.S.A.). The libraries were amplified to obtain sufficient material following the recommendations of the TruSeq sample preparation protocol and quality was assessed using the Qubit 2.0 Fluorometer (Life Technologies) and the Bioanalyzer 2100. Samples were multiplexed with 12 libraries pooled per lane for Illumina sequencing on the HiSeq2500 instrument with $50 \mathrm{bp}$, single-end reads.

The sequencing data were checked for quality control using FastQC. Sequences were aligned to the Arabidopsis Col-0 genome assembly (TAIR10) with TopHat version 2.0.11 (Langmead et al. 2009) and Bowtie version 1.1.0 (Langmead et al. 2009). SAMtools version 0.1.18 (Li et al. 2009) was used to index BAM files for viewing the mapped reads using the Integrative Genomics Viewer genome browser (Robinson et al. 2011). The number of single-mapping reads that overlap each annotated gene was counted using featureCounts (Liao et al. 2014). The counts files were supplied as inputs to EdgeR version 3.0 (Robinson et al. 2010) from the Bioconductor library for statistical analysis of differential gene expression between wild type and mutants. The FDR was controlled at 5\%, using the method of Benjamini and Hochberg (1995). MapMan (Thimm et al. 2004) was used to visualize processes that were enriched in each data set and the logarithmic fold change of gene sets. VirtualPlant 1.3 (Katari et al. 2010) was used for GO analysis to show enrichment for differentially expressed genes with a $P$ value $<0.00001$. Venn diagrams were made with Venny 2.0 (Oliveros 2015). The data discussed in this publication have been deposited in the National Center for Biotechnology Information Gene Expression Omnibus (Edgar et al. 2002)and are accessible through GEO series accession number GSE72548.

\section{qRT-PCR.}

Total RNA was extracted from 12 to 14 seedling roots at 10 days old, grown at $22^{\circ} \mathrm{C}$ at constant light on MS media, using the RNeasy Plus kit as described above. cDNA synthesis was performed using Superscript III (Invitrogen) and oligo-d(T) primers according to the manufacturer's instructions (Invitrogen). Real-time PCR was performed sing SYBR Premix Ex Taq polymerase (TaKaRa Bio Inc., Shiga, Japan) in a ViiATM 7 real-time PCR system (ABI, Foster City, CA, U.S.A.). TUBULIN 4 (At5g44340) was used as housekeeping gene in all reactions with primers previously described ((Cheng et al. 2013). The genespecific primers used for EDS1 (At3g48090) were previously described (Feys et al. 2001). qRT-PCR was performed for three biological replicates for each genotype with three technical replicates. The relative expression of EDS1 was determined using the $2^{-\Delta \Delta C T}$ method (Livak and Schmittgen 2001).

\section{ACKNOWLEDGMENTS}

This work was supported by Hewezi Laboratory startup funds from the University of Tennessee, Institute of Agriculture and by National Science Foundation grants IOS-1022053 and IOS-1238051 to J. J. Kieber and G. E. Schaller.

\section{LITERATURE CITED}

Abramoff, M. D., Magelhaes, P. J., and Ram, S. J. 2004. Image processing with ImageJ. Biophotonics international 11:36-42.

Absmanner, B., Stadler, R., and Hammes, U. Z. 2013. Phloem development in nematode-induced feeding sites: The implications of auxin and cytokinin. Front. Plant Sci. 4:241.

Ahuja, I., de Vos, R. C., Bones, A. M., and Hall, R. D. 2010. Plant molecular stress responses face climate change. Trends Plant Sci. 15:664-674

Argueso, C. T., Ferreira, F. J., Epple, P., To, J. P. C., Hutchison, C. E., Schaller, G. E., Dangl, J. L., Kieber, J. J., and Kieber, J. J. 2012. Twocomponent elements mediate interactions between cytokinin and salicylic acid in plant immunity. PLoS Genet. 8:e1002448.

Argueso, C. T., Ferreira, F. J., and Kieber, J. J. 2009. Environmental perception avenues: The interaction of cytokinin and environmental response pathways. Plant Cell Environ. 32:1147-1160.

Argyros, R. D., Mathews, D. E., Chiang, Y. H., Palmer, C. M., Thibault, D. M., Etheridge, N., Argyros, D. A., Mason, M. G., Kieber, J. J., and Schaller, G. E. 2008. Type B response regulators of Arabidopsis play key roles in cytokinin signaling and plant development. Plant Cell 20: 2102-2116.

Barker, K. R., and Koenning, S. R. 1998. Developing sustainable systems for nematode management. Annu. Rev. Phytopathol. 36:165-205.

Baum, T. J., Wubben, M. J., Hardyy, K. A., Su, H., and Rodermel, S. R. 2000. A screen for Arabidopsis thaliana mutants with altered susceptibility to Heterodera schachtii. J. Nematol. 32:166-173.

Benjamini, Y., and Hochberg, Y. 1995. Controlling the false discovery rate: A practical and powerful approach to multiple testing. J. Roy Stat. Soc. Ser. B Met. 57:289-300.

Bhargava, A., Clabaugh, I., To, J. P., Maxwell, B. B., Chiang, Y. H., Schaller, G. E., Loraine, A., and Kieber, J. J. 2013. Identification of cytokinin-responsive genes using microarray meta-analysis and RNASeq in Arabidopsis. Plant Physiol. 162:272-294.

Bird, A. F., and Loveys, B. R. 1980. The involvement of cytokinins in a host-parasite relationship between the tomato (Lycopersicon esculentum) and a nematode (Meloidogyne javanica). Parasitology 80:497-505.

Bohlmann, H., and Sobczak, M. 2014. The plant cell wall in the feeding sites of cyst nematodes. Front. Plant Sci. 5:89

Brodersen, P., Petersen, M., Bjørn Nielsen, H., Zhu, S., Newman, M. A. Shokat, K. M., Rietz, S., Parker, J., and Mundy, J. 2006. Arabidopsis MAP kinase 4 regulates salicylic acid- and jasmonic acid/ethylenedependent responses via EDS1 and PAD4. Plant J. 47:532-546.

Cabrera, J. F. E., Díaz-Manzano, F. E., Fenoll, C., and Escobar, C. 2015. Developmental pathways mediated by hormones in nematode feeding sites. Pages 167-188 in: Plant Nematode Interactions, Vol 73. Elsevier, Oxford.

Canonne, J., Marino, D., Jauneau, A., Pouzet, C., Brière, C., Roby, D., and Rivas, S. 2011. The Xanthomonas type III effector XopD targets the Arabidopsis transcription factor MYB30 to suppress plant defense. Plant Cell 23:3498-3511. 
Cheng, C. Y., and Kieber, J. J. 2013. The role of cytokinin in ovule development in Arabidopsis. Plant Signal. Behav. 8:e23393.

Cheng, C.-Y., Mathews, D. E., Schaller, G. E., and Kieber, J. J. 2013. Cytokinin-dependent specification of the functional megaspore in the Arabidopsis female gametophyte. Plant J. 73:929-940.

Chitwood, D. J. 2003. Research on plant-parasitic nematode biology conducted by the United States Department of Agriculture-Agricultural Research Service. Pest Manag. Sci. 59:748-753.

Choi, J., Choi, D., Lee, S., Ryu, C. M., and Hwang, I. 2011. Cytokinins and plant immunity: Old foes or new friends? Trends Plant Sci. 16: 388-394.

Choi, J., Huh, S. U., Kojima, M., Sakakibara, H., Paek, K. H., and Hwang, I. 2010. The cytokinin-activated transcription factor ARR2 promotes plant immunity via TGA3/NPR1-dependent salicylic acid signaling in Arabidopsis. Dev. Cell 19:284-295.

Claeys, M., Messens, E., Van Montagu, M., and Schell, J. 1978. GC/MS determination of cytokinins in Agrobacterium tumefaciens cultures. Fresenius J. Anal. Chem. 290:125-126.

Clough, S. J., and Bent, A. F. 1998. Floral dip: A simplified method for Agrobacterium-mediated transformation of Arabidopsis thaliana. Plant J. 16:735-743.

Cui, F., Brosché, M., Sipari, N., Tang, S., and Overmyer, K. 2013. Regulation of ABA dependent wound induced spreading cell death by MYB108. New Phytol. 200:634-640.

De Meutter, J., Tytgat, T., Witters, E., Gheysen, G., Van Onckelen, H., and Gheysen, G. 2003. Identification of cytokinins produced by the plant parasitic nematodes Heterodera schachtii and Meloidogyne incognita. Mol. Plant Pathol. 4:271-277.

Dean, J. V., and Delaney, S. P. 2008. Metabolism of salicylic acid in wildtype, ugt $74 f 1$ and ugt $74 f 2$ glucosyltransferase mutants of Arabidopsis thaliana. Physiol. Plant. 132:417-425.

Depuydt, S., Dolezal, K., Van Lijsebettens, M., Moritz, T., Holsters, M., and Vereecke, D. 2008. Modulation of the hormone setting by Rhodococcus fascians results in ectopic KNOX activation in Arabidopsis. Plant Physiol. 146:1267-1281.

Dimalla, G. G., and van Staden, J. 1977. Cytokinins in the root-knot nematode, Meloidogyne incognita. Plant Sci. Lett. 10:25-29.

Earley, K. W., Haag, J. R., Pontes, O., Opper, K., Juehne, T., Song, K., and Pikaard, C. S. 2006. Gateway-compatible vectors for plant functional genomics and proteomics. Plant J. 45:616-629.

Edgar, R., Domrachev, M., and Lash, A. E. 2002. Gene Expression Omnibus: NCBI gene expression and hybridization array data repository. Nucleic Acids Res. 30:207-210.

Feys, B. J., Moisan, L. J., Newman, M. A., and Parker, J. E. 2001. Direct interaction between the Arabidopsis disease resistance signaling proteins, EDS1 and PAD4. EMBO (Eur. Mol. Biol. Organ.) J. 20: 5400-5411.

Grunewald, W., Karimi, M., Wieczorek, K., Van de Cappelle, E., Wischnitzki, E., Grundler, F., Inzé, D., Beeckman, T., and Gheysen, G. 2008. A role for AtWRKY23 in feeding site establishment of plantparasitic nematodes. Plant Physiol. 148:358-368.

Haegeman, A., Mantelin, S., Jones, J. T., and Gheysen, G. 2012. Functional roles of effectors of plant-parasitic nematodes. Gene 492:19-31.

Hejátko, J., Ryu, H., Kim, G. T., Dobesová, R., Choi, S., Choi, S. M., Soucek, P., Horák, J., Pekárová, B., Palme, K., Brzobohaty, B., and Hwang, I. 2009. The histidine kinases CYTOKININ-INDEPENDENT1 and ARABIDOPSIS HISTIDINE KINASE2 and 3 regulate vascular tissue development in Arabidopsis shoots. Plant Cell 21:2008-2021.

Hewezi, T., and Baum, T. J. 2013. Manipulation of plant cells by cyst and root-knot nematode effectors. Mol. Plant-Microbe Interact. 26:9-16.

Hewezi, T., Howe, P., Maier, T. R., Hussey, R. S., Mitchum, M. G., Davis, E. L., and Baum, T. J. 2008. Cellulose binding protein from the parasitic nematode Heterodera schachtii interacts with Arabidopsis pectin methylesterase: Cooperative cell wall modification during parasitism Plant Cell 20:3080-3093.

Hewezi, T., Juvale, P. S., Piya, S., Maier, T. R., Rambani, A., Rice, J. H., Mitchum, M. G., Davis, E. L., Hussey, R. S., and Baum, T. J. 2015. The cyst nematode effector protein $10 \mathrm{~A} 07$ targets and recruits host posttranslational machinery to mediate its nuclear trafficking and to promote parasitism in Arabidopsis. Plant Cell 27:891-907

Hewezi, T., Maier, T. R., Nettleton, D., and Baum, T. J. 2012. The Arabidopsis microRNA396- $G R F_{1} / G R F_{3}$ regulatory module acts as a developmental regulator in the reprogramming of root cells during cyst nematode infection. Plant Physiol. 159:321-335.

Hewezi, T., Piya, S., Richard, G., and Rice, J. H. 2014. Spatial and temporal expression patterns of auxin response transcription factors in the syncytium induced by the beet cyst nematode Heterodera schachtii in Arabidopsis. Mol. Plant Pathol. 15:730-736.
Higuchi, M., Pischke, M. S., Mähönen, A. P., Miyawaki, K., Hashimoto, Y., Seki, M., Kobayashi, M., Shinozaki, K., Kato, T., Tabata, S., Helariutta, Y., Sussman, M. R., and Kakimoto, T. 2004. In planta functions of the Arabidopsis cytokinin receptor family. Proc. Natl. Acad. Sci. U.S.A. 101:8821-8826.

Hill, K., Mathews, D. E., Kim, H. J., Street, I. H., Wildes, S. L., Chiang, Y. H., Mason, M. G., Alonso, J. M., Ecker, J. R., Kieber, J. J., and Schaller, G. E. 2013. Functional characterization of type-B response regulators in the Arabidopsis cytokinin response. Plant Physiol. 162: 212-224.

Hirose, N., Takei, K., Kuroha, T., Kamada-Nobusada, T., Hayashi, H., and Sakakibara, H. 2008. Regulation of cytokinin biosynthesis, compartmentalization and translocation. J. Exp. Bot. 59:75-83.

Hoth, S., Schneidereit, A., Lauterbach, C., Scholz-Starke, J., and Sauer, N. 2005. Nematode infection triggers the de novo formation of unloading phloem that allows macromolecular trafficking of green fluorescent protein into syncytia. Plant Physiol. 138:383-392.

Hubert, D. A., Tornero, P., Belkhadir, Y., Krishna, P., Takahashi, A., Shirasu, K., and Dangl, J. L. 2003. Cytosolic HSP90 associates with and modulates the Arabidopsis RPM1 disease resistance protein. EMBO (Eur. Mol. Biol. Organ.) J. 22:5679-5689.

Hutchison, C. E., Li, J., Argueso, C., Gonzalez, M., Lee, E., Lewis, M. W. Maxwell, B. B., Perdue, T. D., Schaller, G. E., Alonso, J. M., Ecker, J. R., and Kieber, J. J. 2006. The Arabidopsis histidine phosphotransfer proteins are redundant positive regulators of cytokinin signaling. Plant Cell 18:3073-3087.

Hwang, H. H., Wang, M. H., Lee, Y. L., Tsai, Y. L., Li, Y. H., Yang, F. J., Liao, Y. C., Lin, S. K., and Lai, E. M. 2010. Agrobacterium-produced and exogenous cytokinin-modulated Agrobacterium-mediated plant transformation. Mol. Plant Pathol. 11:677-690.

Hwang, I., and Sheen, J. 2001. Two-component circuitry in Arabidopsis cytokinin signal transduction. Nature 413:383-389.

Inoue, T., Higuchi, M., Hashimoto, Y., Seki, M., Kobayashi, M., Kato, T., Tabata, S., Shinozaki, K., and Kakimoto, T. 2001. Identification of CRE1 as a cytokinin receptor from Arabidopsis. Nature 409:1060-1063.

Ithal, N., Recknor, J., Nettleton, D., Maier, T., Baum, T. J., and Mitchum, M. G. 2007. Developmental transcript profiling of cyst nematode feeding cells in soybean roots. Mol. Plant-Microbe Interact. 20:510-525.

Kandoth, P. K., Ithal, N., Recknor, J., Maier, T., Nettleton, D., Baum, T. J., and Mitchum, M. G. 2011. The soybean Rhgl locus for resistance to the soybean cyst nematode Heterodera glycines regulates the expression of a large number of stress- and defense-related genes in degenerating feeding cells. Plant Physiol. 155:1960-1975.

Katari, M. S., Nowicki, S. D., Aceituno, F. F., Nero, D., Kelfer, J., Thompson, L. P., Cabello, J. M., Davidson, R. S., Goldberg, A. P. Shasha, D. E., Coruzzi, G. M., and Gutiérrez, R. A. 2010. VirtualPlant: A software platform to support systems biology research. Plant Physiol. 152:500-515

Kieber, J. J., and Schaller, G. E. 2014. Cytokinins. Arabidopsis Book 12 e0168.

Kim, K. C., Lai, Z., Fan, B., and Chen, Z. 2008. Arabidopsis WRKY38 and WRKY62 transcription factors interact with histone deacetylase 19 in basal defense. Plant Cell 20:2357-2371.

Kuroha, T., Tokunaga, H., Kojima, M., Ueda, N., Ishida, T., Nagawa, S. Fukuda, H., Sugimoto, K., and Sakakibara, H. 2009. Functional analyses of LONELY GUY cytokinin-activating enzymes reveal the importance of the direct activation pathway in Arabidopsis. Plant Cell 21:3152-3169.

Kyndt, T., Denil, S., Haegeman, A., Trooskens, G., Bauters, L., Van Criekinge, W., De Meyer, T., and Gheysen, G. 2012. Transcriptional reprogramming by root knot and migratory nematode infection in rice. New Phytol. 196:887-900.

Langmead, B., Trapnell, C., Pop, M., and Salzberg, S. L. 2009. Ultrafast and memory-efficient alignment of short DNA sequences to the human genome. Genome Biol. 10:R25.

Li, H., Handsaker, B., Wysoker, A., Fennell, T., Ruan, J., Homer, N., Marth, G., Abecasis, G., Durbin, R., Subgroup, G. P. D. P., and 1000 Genome Project Data Processing Subgroup. 2009. The sequence alignment/map format and SAMtools. Bioinformatics 25:2078-2079.

Liao, Y., Smyth, G. K., and Shi, W. 2014. featureCounts: An efficient general purpose program for assigning sequence reads to genomic features. Bioinformatics 30:923-930.

Livak, K. J., and Schmittgen, T. D. 2001. Analysis of relative gene expression data using real-time quantitative PCR and the $2^{-\Delta \Delta C T}$ method. Methods 25:402-408.

Lohar, D. P., Schaff, J. E., Laskey, J. G., Kieber, J. J., Bilyeu, K. D., and Bird, D. M. 2004. Cytokinins play opposite roles in lateral roo formation, and nematode and rhizobial symbioses. Plant J. 38 : 203-214. 
López-Carbonell, M., Moret, A., and Nadal, M. 1998. Changes in cell ultrastructure and zeatin riboside concentrations in Hedera helix, Pelargonium zonale, Prunus avium, and Rubus ulmifolius leaves infected by fungi. Plant Dis. 82:914-918.

Lorenzo, O., Piqueras, R., Sánchez-Serrano, J. J., and Solano, R. 2003. ETHYLENE RESPONSE FACTOR1 integrates signals from ethylene and jasmonate pathways in plant defense. Plant Cell 15:165-178.

Mason, M. G., Mathews, D. E., Argyros, D. A., Maxwell, B. B., Kieber, J. J., Alonso, J. M., Ecker, J. R. S., and Schaller, G. E. 2005. Multiple type-B response regulators mediate cytokinin signal transduction in Arabidopsis. Plant Cell 17:3007-3018.

Matsumoto-Kitano, M., Kusumoto, T., Tarkowski, P., Kinoshita-Tsujimura, K., Václavíková, K., Miyawaki, K., and Kakimoto, T. 2008. Cytokinins are central regulators of cambial activity. Proc. Natl. Acad. Sci. U.S.A. 105:20027-20031.

Mok, D. W., and Mok, M. C. 2001. Cytokinin metabolism and action. Annu. Rev. Plant Physiol. Plant Mol. Biol. 52:89-118.

Naseem, M., and Dandekar, T. 2012. The role of auxin-cytokinin antagonism in plant-pathogen interactions. PLoS Pathog. 8:e1003026.

Nishimura, C., Ohashi, Y., Sato, S., Kato, T., Tabata, S., and Ueguchi, C. 2004. Histidine kinase homologs that act as cytokinin receptors possess overlapping functions in the regulation of shoot and root growth in Arabidopsis. Plant Cell 16:1365-1377.

Oliveros, J. C. 2015. Venny. An interactive tool for comparing lists with Venn's diagrams. http://bioinfogp.cnb.csic.es/tools/venny/index.html. Computational Genomics Service, Centro Nacional de Biotecnología, Madrid.

Ozalvo, R., Cabrera, J., Escobar, C., Christensen, S. A., Borrego, E. J., Kolomiets, M. V., Castresana, C., Iberkleid, I., and Brown Horowitz, S. 2014. Two closely related members of Arabidopsis 13-lipoxygenases (13-LOXs), LOX3 and LOX4, reveal distinct functions in response to plant-parasitic nematode infection. Mol. Plant Pathol. 15:319-332.

Penninckx, I. A., Thomma, B. P., Buchala, A., Métraux, J. P., and Broekaert, W. F. 1998. Concomitant activation of jasmonate and ethylene response pathways is required for induction of a plant defensin gene in Arabidopsis. Plant Cell 10:2103-2113.

Pertry, I., Václavíková, K., Depuydt, S., Galuszka, P., Spíchal, L., Temmerman, W., Stes, E., Schmülling, T., Kakimoto, T., Van Montagu, M. C. E., Strnad, M., Holsters, M., Tarkowski, P., and Vereecke, D. 2009. Identification of Rhodococcus fascians cytokinins and their modus operandi to reshape the plant. Proc. Natl. Acad. Sci. U.S.A. 106:929-934.

Quentin, M., Hewezi, T., Damiani, I., Abad, P., Baum, T., and Favery, B. 2013. How pathogens affect root structure. Root Genomics and Soil Interactions. M. Crespi, ed. Blackwell Publishing Ltd, Oxford, U.K.

Riefler, M., Novak, O., Strnad, M., and Schmülling, T. 2006. Arabidopsis cytokinin receptor mutants reveal functions in shoot growth, leaf senescence, seed size, germination, root development, and cytokinin metabolism. Plant Cell 18:40-54.

Robert-Seilaniantz, A., Grant, M., and Jones, J. D. 2011. Hormone crosstalk in plant disease and defense: More than just jasmonate-salicylate antagonism. Annu. Rev. Phytopathol. 49:317-343.

Robert-Seilaniantz, A., Navarro, L., Bari, R., and Jones, J. D. G. 2007. Pathological hormone imbalances. Curr. Opin. Plant Biol. 10:372-379.

Robinson, J. T., Thorvaldsdóttir, H., Winckler, W., Guttman, M., Lander, E. S., Getz, G., and Mesirov, J. P. 2011. Integrative genomics viewer. Nat. Biotechnol. 29:24-26.

Robinson, M. D., McCarthy, D. J., and Smyth, G. K. 2010. edgeR: A Bioconductor package for differential expression analysis of digital gene expression data. Bioinformatics 26:139-140.

Schaller, F. 2001. Enzymes of the biosynthesis of octadecanoid-derived signalling molecules. J. Exp. Bot. 52:11-23.

Schön, M., Töller, A., Diezel, C., Roth, C., Westphal, L., Wiermer, M., and Somssich, I. E. 2013. Analyses of wrky 18 wrky40 plants reveal critical roles of SA/EDS1 signaling and indole-glucosinolate biosynthesis for Golovinomyces orontii resistance and a loss-of resistance towards Pseudomonas syringae pv. tomato AvrRPS4. Mol. Plant-Microbe Interact. 26:758-767.
Shapiro, A. D., and Zhang, C. 2001. The role of NDR1 in avirulence genedirected signaling and control of programmed cell death in Arabidopsis. Plant Physiol. 127:1089-1101.

Shirasu, K. 2009. The HSP90-SGT1 chaperone complex for NLR immune sensors. Annu. Rev. Plant Biol. 60:139-164.

Sijmons, P. C., Grundler, F. M. W., von Mende, N., Burrows, P. R., and Wyss, U. 1991. Arabidopsis thaliana as a new model for plant-parasitic nematodes. Plant J. 1:245-254.

Suzuki, T., Miwa, K., Ishikawa, K., Yamada, H., Aiba, H., and Mizuno, T. 2001. The Arabidopsis sensor His-kinase, AHk4, can respond to cytokinins. Plant Cell Physiol. 42:107-113.

Szakasits, D., Heinen, P., Wieczorek, K., Hofmann, J., Wagner, F., Kreil, D. P., Sykacek, P., Grundler, F. M. W., and Bohlmann, H. 2009. The transcriptome of syncytia induced by the cyst nematode Heterodera schachtii in Arabidopsis roots. Plant J. 57:771-784.

Takahashi, A., Casais, C., Ichimura, K., and Shirasu, K. 2003. HSP90 interacts with RAR1 and SGT1 and is essential for RPS2-mediated disease resistance in Arabidopsis. Proc. Natl. Acad. Sci. U.S.A. 100: 11777-11782.

Thao, N. P., Chen, L., Nakashima, A., Hara, S., Umemura, K., Takahashi, A., Shirasu, K., Kawasaki, T., and Shimamoto, K. 2007. RAR1 and HSP90 form a complex with Rac/Rop GTPase and function in innateimmune responses in rice. Plant Cell 19:4035-4045.

Thimm, O., Bläsing, O., Gibon, Y., Nagel, A., Meyer, S., Krüger, P., Selbig, J., Müller, L. A., Rhee, S. Y., and Stitt, M. 2004. MAPMAN: A userdriven tool to display genomics data sets onto diagrams of metabolic pathways and other biological processes. Plant J. 37:914-939.

To, J. P. C., Haberer, G., Ferreira, F. J., Deruère, J., Mason, M. G., Schaller, G. E., Alonso, J. M., Ecker, J. R., and Kieber, J. J. 2004. Type-A Arabidopsis response regulators are partially redundant negative regulators of cytokinin signaling. Plant Cell 16:658-671.

Ueguchi, C., Sato, S., Kato, T., and Tabata, S. 2001. The AHK4 gene involved in the cytokinin-signaling pathway as a direct receptor molecule in Arabidopsis thaliana. Plant Cell Physiol. 42:751-755.

van Verk, M. C., Bol, J. F., and Linthorst, H. J. 2011. WRKY transcription factors involved in activation of SA biosynthesis genes. BMC Plant Biol. 11:89.

Walters, D. R., and McRoberts, N. 2006. Plants and biotrophs: A pivotal role for cytokinins? Trends Plant Sci. 11:581-586.

Walters, D. R., McRoberts, N., and Fitt, B. D. L. 2008. Are green islands red herrings? Significance of green islands in plant interactions with pathogens and pests. Biol. Rev.83:79-102.

Wang, W., Vinocur, B., Shoseyov, O., and Altman, A. 2004. Role of plant heat-shock proteins and molecular chaperones in the abiotic stress response. Trends Plant Sci. 9:244-252.

Wubben, M. J., 2nd, Su, H., Rodermel, S. R., and Baum, T. J. 2001. Susceptibility to the sugar beet cyst nematode is modulated by ethylene signal transduction in Arabidopsis thaliana. Mol. Plant-Microbe Interact. 14:1206-1212.

Yamada, H., Suzuki, T., Terada, K., Takei, K., Ishikawa, K., Miwa, K., Yamashino, T., and Mizuno, T. 2001. The Arabidopsis AHK4 histidine kinase is a cytokinin-binding receptor that transduces cytokinin signals across the membrane. Plant Cell Physiol. 42:1017-1023.

Zhang, W., To, J. P., Cheng, C. Y., Schaller, G. E., and Kieber, J. J. 2011. Type-A response regulators are required for proper root apical meristem function through post-transcriptional regulation of PIN auxin efflux carriers. Plant J. 68:1-10.

Zürcher, E., Tavor-Deslex, D., Lituiev, D., Enkerli, K., Tarr, P. T., and Müller, B. 2013. A robust and sensitive synthetic sensor to monitor the transcriptional output of the cytokinin signaling network in planta. Plant Physiol. 161:1066-1075.

\section{AUTHOR-RECOMMENDED INTERNET RESOURCE}

FastQC software:

http://www.bioinformatics.babraham.ac.uk/projects/fastqc 